\title{
FFR in Everyday Use: The Case of Left Ventricular Dysfunction
}

\author{
Piroth $Z^{*}$ \\ Department of Adult Cardiology, Hungarian Institute of Cardiology, Budapest, Hungary
}

*Corresponding author: Piroth Z, Department of Adult Cardiology, Hungarian Institute of Cardiology, Budapest, Hungary, Tel: 0036209752849, E-mail: zpiroth@gmail.com

Citation: Piroth Z (2018) FFR in Everyday Use: The Case of Left Ventricular Dysfunction. J Card Disord Therapy 1: 102

Article history: Received: 18 January 2018, Accepted: 24 February 2018, Published: 26 February 2018

\begin{abstract}
Patients with severe left ventricular dysfunction frequently undergo coronary angiography to rule out coronary artery disease. Here we describe the case of a 58-year-old man without angina and any non-invasive proof of myocardial ischaemia who was sent for invasive coronary angiography. Apart from the subtotal, proximal occlusion of the dominant right coronary artery, a $70 \%$ diagonal stenosis was found. After RCA PCI, FFR-guided diagonal PCI was also carried out. Post-PCI FFR however revealed the hitherto unnoticed significant left main ostial stenosis and allowed complete functional revascularisation.
\end{abstract}

Keywords: FFR; Left Ventricular Dysfunction

\section{Introduction}

A 58-year old man with the history of hypertension was seen by a cardiologist for hypertension diagnosed three years before and treated by metoprolol succinate, valsartan, indapamide and amlodipine. His ECG showed right bundle branch block and echocardiography revealed severely depressed left ventricular dysfunction with an ejection fraction of $30 \%$. He was referred to our tertiary care center for diagnostic coronary angiography. Of note, he had never had angina, dyspnea or syncope. He gave a past history of tobacco smoking and moderate alcohol consumption.

Echocardiography revealed diffuse hypokinesia with almost akinetic inferior segments, a dilated, hypo contractile left ventricle (LVEDD $71 \mathrm{~mm}$, LVESD 60 mm, LVEDV 273 ml, LVESV $171 \mathrm{ml}$, LVEF 37\%), dilated atria (left atrium 65 mm, right atrium 65 $\mathrm{mm}$ ), left ventricular hypertrophy (IVS $15 \mathrm{~mm}$ ). The valves and the right heart seemed normal. Chest XR gave no sign of left ventricular failure. Albeit the patient had had no angina ever and no non-invasive test had been performed for the evaluation of ischemic heart disease, a diagnostic coronary angiography using the transradial approach was performed to rule out coronary artery disease as a cause of left ventricular dysfunction.

The left coronary angiogram showed a 70\% stenosis in the second diagonal, mild LAD and Cx disease and retrograde filling of the dominant right coronary artery up to the crux (Figure 1, 2 and 3). Upon right coronary angiography, we found a long, sub totally occluded proximal segment with a TIMI II flow in the mid-RCA (Figure 4). An ad hoc PCI of the dominant right coronary artery was decided. A 6F AL1, 0 guiding catheter allowed the passage of a Pilot-150 guidewire, and the lesion was successfully dilated by a 1,2x15 mm MiniTrek, 1,25x10 mm Ryujin and a 2,0x30 mm Apex balloon and was stented by a 3,0x34 mm Resolute Integrity DES postdilated by a 3,0x15 mm NC Quantum Apex balloon at 20 atm. The angiographic result seemed acceptable (Figure 5).

Since we had no proof of the ischemia-producing potential of the lesion in the diagonal branch, pressure-derived fractional flow reserve (FFR) measurement was performed with the use of a PressureWire Certus (St. Jude Medical). A 6F VL3, 0 guiding catheter was used after equalizing the pressures measured by the PressureWire and the guiding catheter in the ascending aorta. The PressureWire was advanced in the diagonal branch and maximal hyperemia was achieved by administering $200 \mu \mathrm{g}$ nitroglycerol and $150 \mu \mathrm{g}$ adenosine intracoronarily. An extremely low FFR of 0,33 was found therefore PCI of the diagonal was decided. After predilation with a 2,0x15 mm balloon, a 2,5x15 mm PRO-Kinetic bare metal stent was implanted at 12 atm, achieving satisfactory angiographic result (Figure 6). Since post-PCI FFR is regularly measured at our center, $200 \mu \mathrm{g}$ nitroglycerol and $150 \mu \mathrm{g}$ adenosine were given intracoronarily again. 


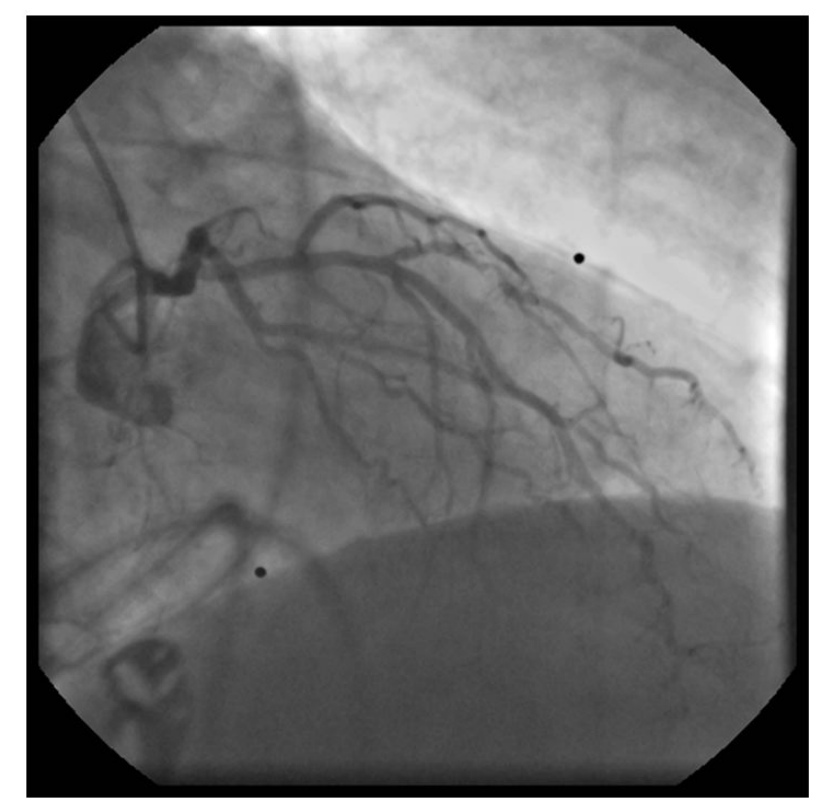

Figure 1: Left coronary angiogram from RAO cranial projection prior to PCI

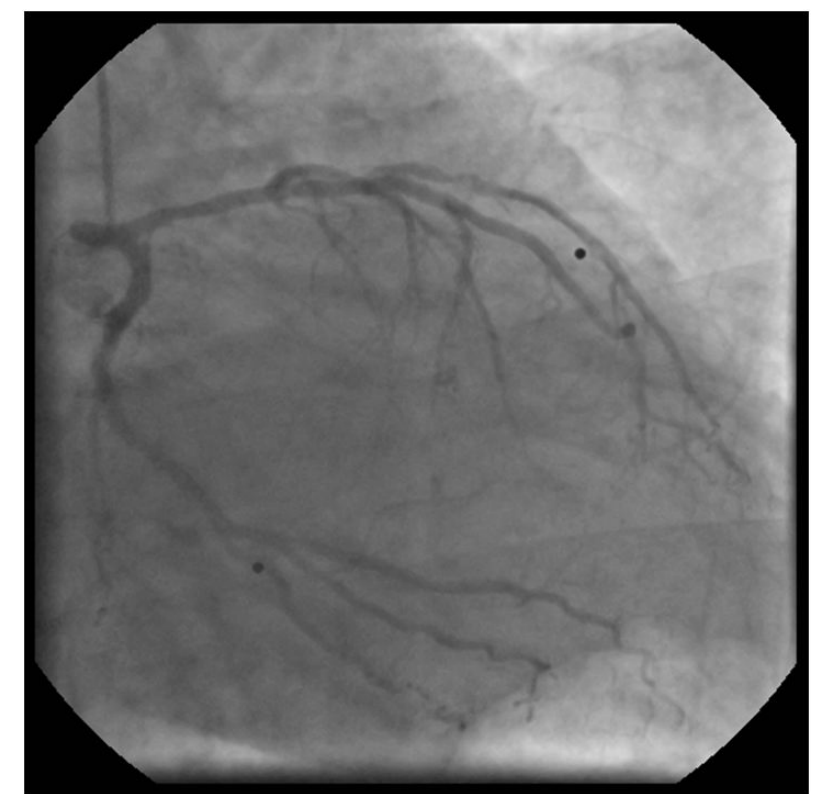

Figure 2: Left coronary angiogram from RAO caudal projection prior to PCI

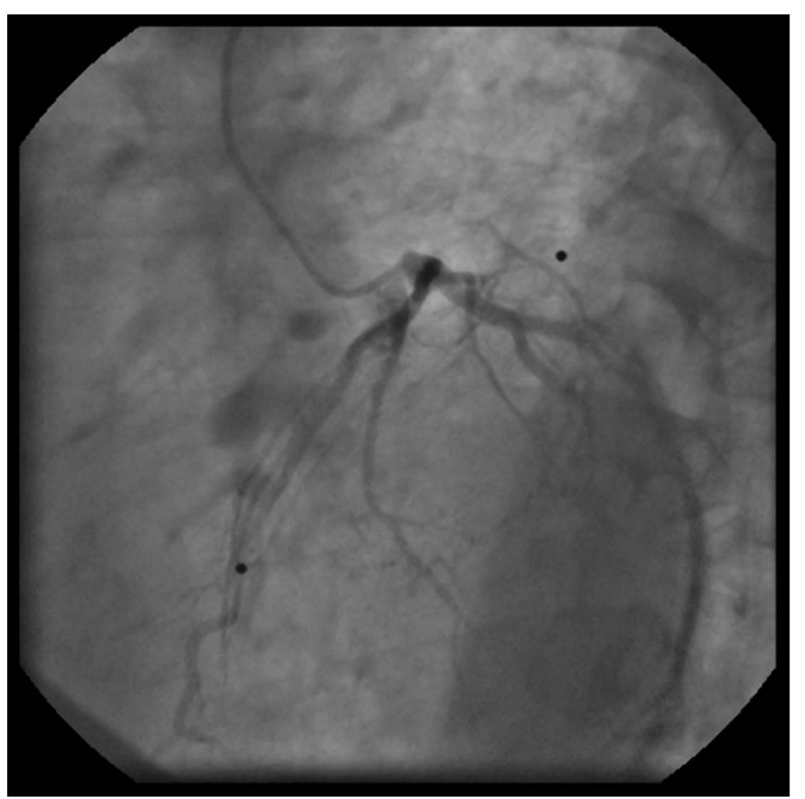

Figure 3: Left coronary angiogram from LAO cranial projection prior to PCI 


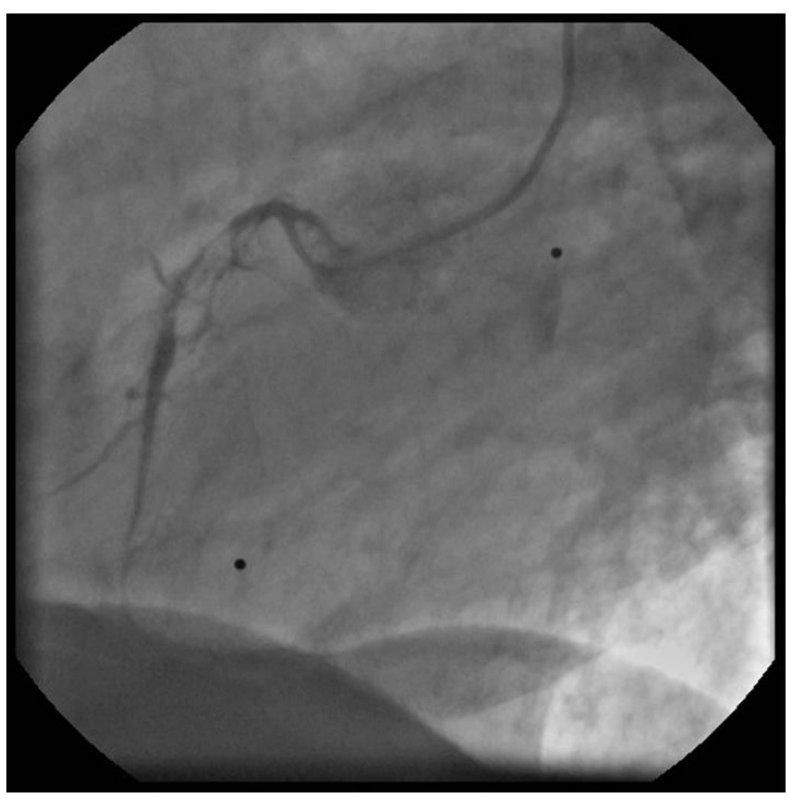

Figure 4: Right coronary angiogram prior to PCI

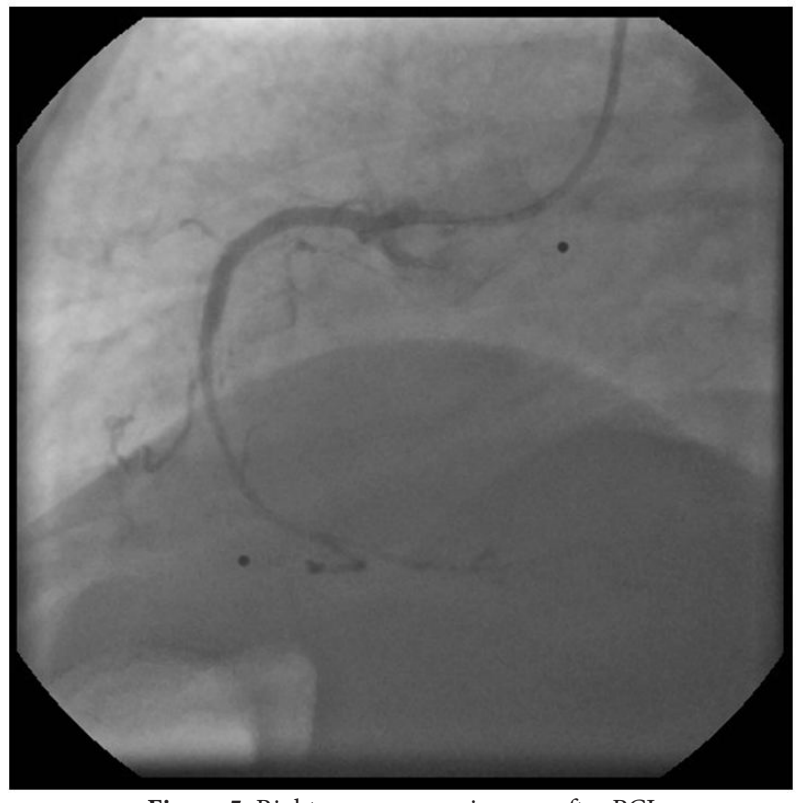

Figure 5: Right coronary angiogram after PCI

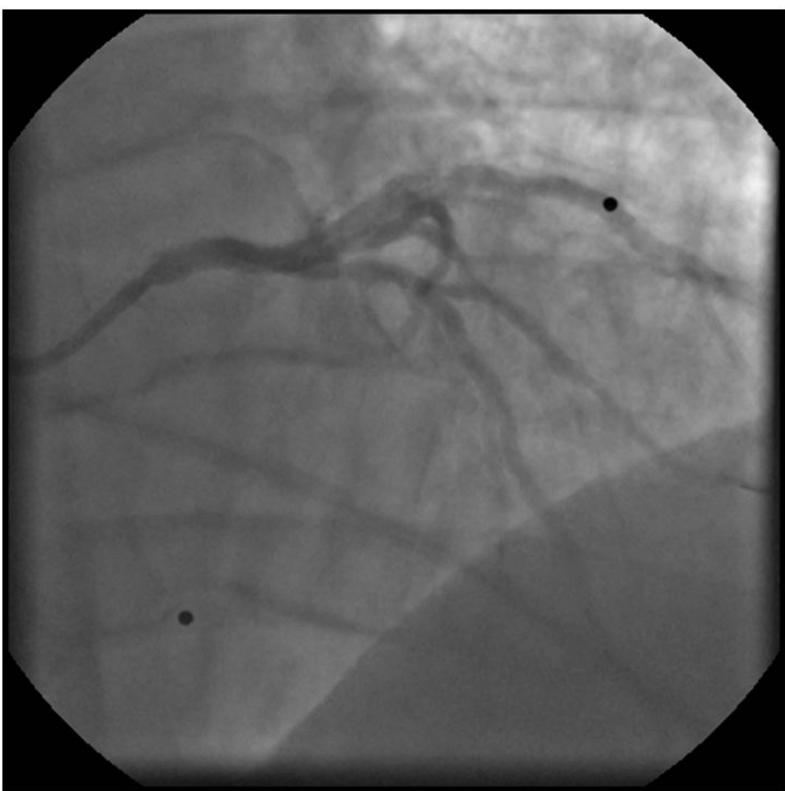

Figure 6: Left coronary angiogram after diagonal PCI 
We noted that deep seating of the guiding catheter resulted in a very small gradient measured between the guiding catheter and the PressureWire but unseating the catheter revealed - much to our disappointment - a low FFR of 0,72. The tracing taken is shown by (Figure 7). Upon closer inspection, the aortic curve in the deep seating position seemed ventricularized which called our attention to the hitherto neglected left ostial lesion which seemed mild on angiography. So finally left main ostial stenting was performed by implanting a 4,0x15 mm Xience V DES and postdilating it by a 4,5x15 mm NC balloon at 22 atm (Figure 8). Final post-PCI FFR was 0,85 and pull-back under hyperemia revealed no focal step-up in the distal (coronary) pressure, proving that the remaining gradient is caused by the diffuse, mild coronary atherosclerosis. The patient was discharged on ASA $100 \mathrm{mg}$ qd, clopidogrel $75 \mathrm{mg}$ qd, bisoprolol $5 \mathrm{mg}$ qd, valsartan $80 \mathrm{mg}$ b.i.d., atorvastatin $30 \mathrm{mg}$ qd, pantoprazole $40 \mathrm{mg}$ qd.

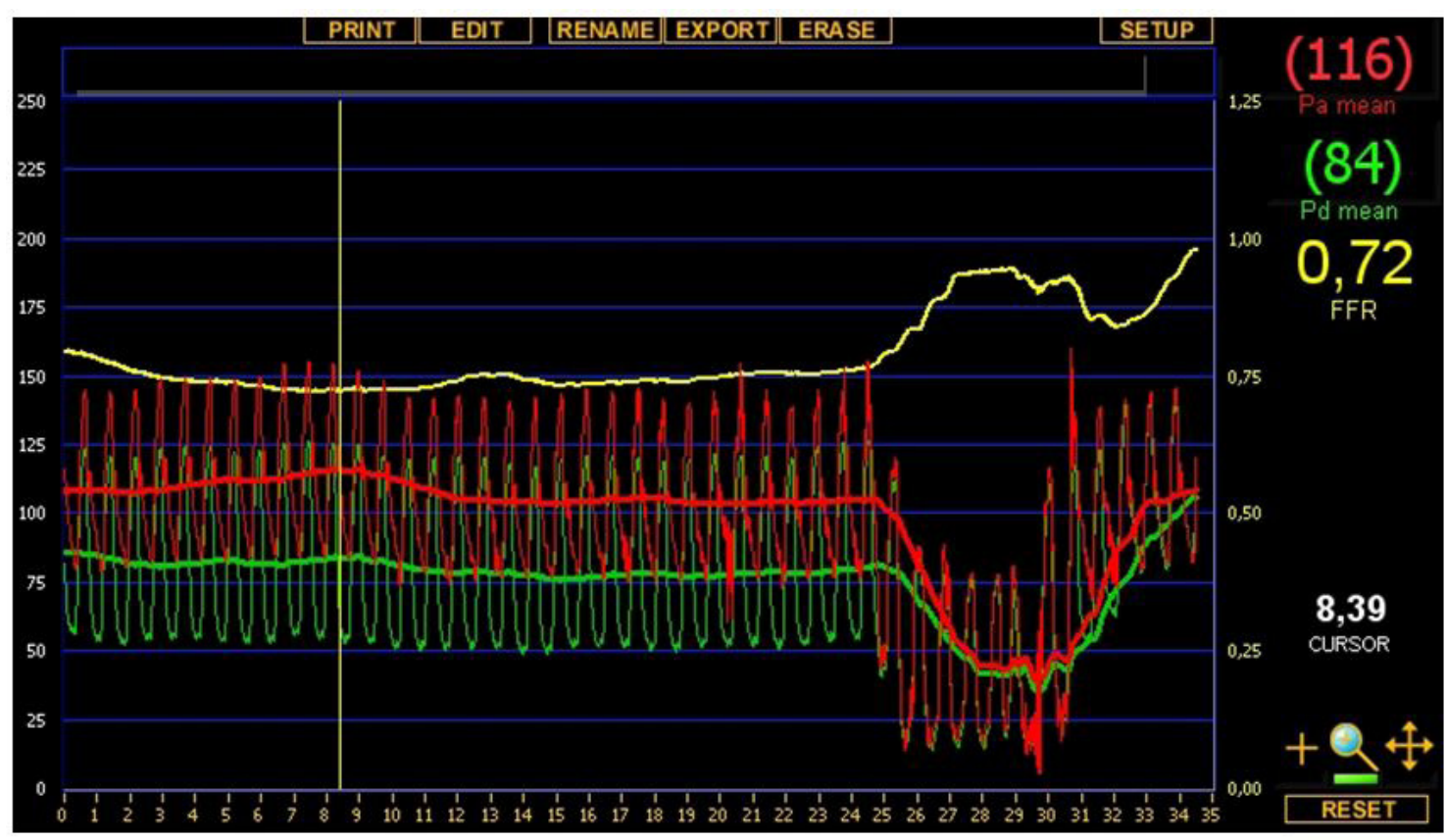

Figure 7: FFR tracing after diagonal PCI

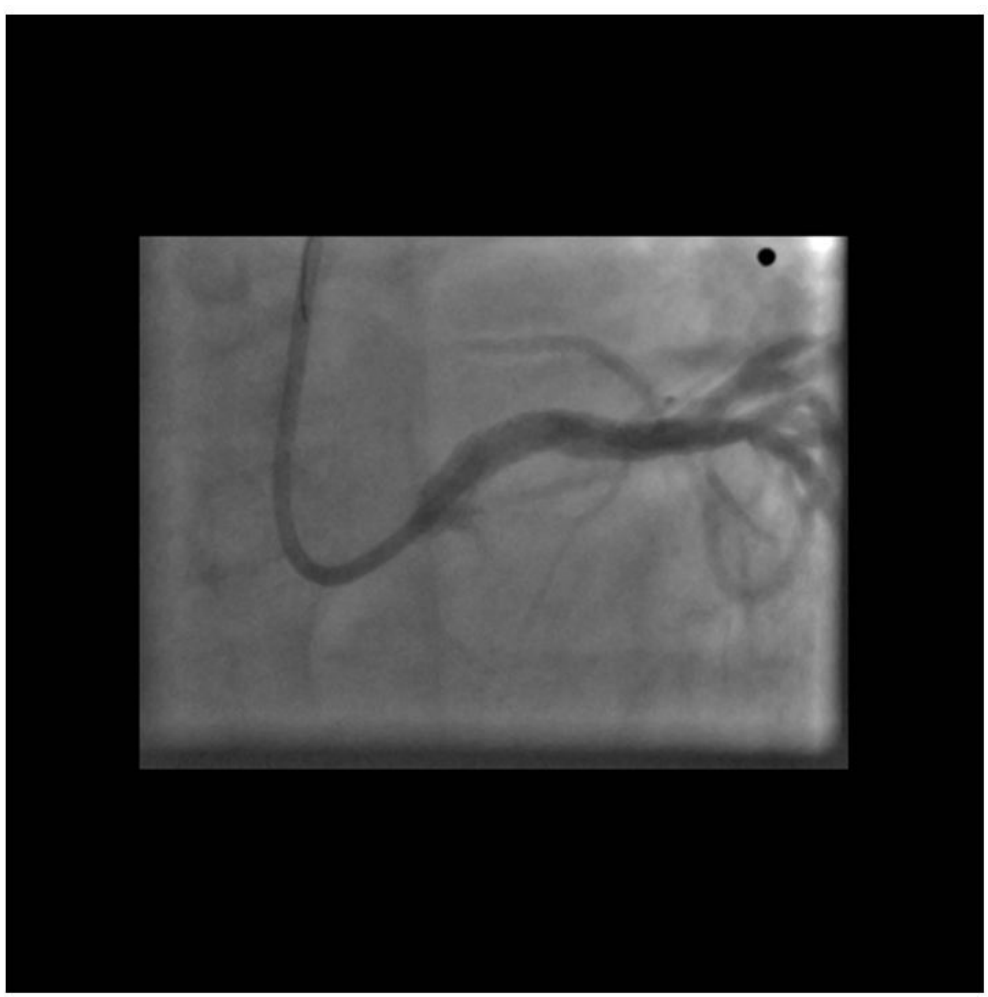

Figure 8: Left coronary angiogram after left main PCI

A planned recoronary angiography 6 months later showed subtotal in-stent restenosis in the BMS of the diagonal treated by plain old balloon angioplasty with satisfactory angiographic result, and no restenosis was found in the drug eluting stents of the left main and the right coronary arteries. The patient continued to be symptom-free. 3 years after the initial PCI recoronary angiography showed no LM, RCA or diagonal in-stent restenosis or any significant de novo lesion. 


\section{Discussion}

It is noted worldwide that a growing percentage of patients scheduled to undergo elective coronary angiography and potentially ad hoc PCI arrive in the catheterization laboratory without thorough prior non-invasive workup [1]. This results in delineating the coronary anatomy before any functional information of the lesions found is available. Since a notoriously loose relationship existing between the prognosis and anatomical extent of coronary artery disease is long known, basing the decisions of revascularisation on pure anatomical grounds is considered suboptimal [2,3]. Current guidelines require non-invasive demonstration of ischaemia before elective PCI [4]. Lately, the multicenter randomized FAME Trial showed the superiority of FFR-guided percutaneous coronary revascularization compared to the traditional, angiography-guided approach [5-7]. Taken these together, FFR proves to be a very valuable tool in managing the ever-growing number of elective patients sent to our cath labs for coronary angiography [8].

The case described above is considered to have several points of interest. The patient represents an everyday case for ruling out coronary artery disease in left ventricular dysfunction. Albeit the subtotal proximal occlusion of the dominant right coronary artery, in light of the echocardiographic finding of severe hypokinesia (no akinesia or scarring) of the inferior wall, results most probably in large myocardial ischemia, therefore revascularisation of the RCA can be judged to be appropriate, that of a noncritical lesion of a secondary vessel, like a diagonal branch, is certainly to be decided by objective functional measures, the most ready-to-use in the cath lab being FFR.

FFR in this case not only showed that the diagonal had a functionally significant lesion, but by measuring the post-PCI FFR as a quality control, we were able to demonstrate that a prognostically much more important lesion, that of the left main, needed revascularisation. Needless to say, a significant LM stenosis and dominant RCA occlusion in a 58-year-old patient with severe left ventricular dysfunction is a clear indication for CABG, however on angiography only RCA and diagonal disease was diagnosed. Of note, the functional significance of the left main stenosis could only be shown without any doubt after the recanalization of what seems to have been an old subocclusion of the dominant right coronary artery, that is to say after reducing the perfusion territory of the left coronary artery to its anatomical limits - collaterals perfusing retrogradely a chronically occluded contralateral coronary artery are proven to close promptly after successful recanalization of the occlusion. In this case, after RCA PCI, no further retrograde filling of the RCA was seen. Otherwise it could have been argued that a low FFR in the left coronary system was related to the retrograde filling of the dominant RCA. Proving the functional significance of the left main stenosis in light of the occlusion of the RCA, makes the case for considering ischemic heart disease a very important cause of left ventricular dysfunction of this man without any angina ever.

In the bare metal stent era, a large, multicenter post-PCI FFR Registry showed the prognostic power of FFR measured after anatomically successful PCI [9]. There is cumulating evidence that post-PCI FFR has prognostic power in the DES era also [1015]. After anatomically successful PCI, not having a post-PCI FFR of 1.0 can have 4 reasons: diffuse disease (not amenable to focal therapy like PCI), neglected secondary lesion (like in our case), suboptimal stenting (i. e. leaving too high hyperemic pressure gradient across the deployed stent, rarely the case using high pressure postdilatation), and drift $[11,16]$.

In the above case, both the diagonal and the left main could be revascularized by using the PressureWire alone, without the need of any workhorse wires and the final post-PCI FFR could also be measured.

The very case is a memento to demonstrate a rare, but serious potential technical caveat of FFR measurement: ostial disease. If found, it is always a case to use systemic hyperemia (i. e. intravenous administration of adenosine at $140 \mu \mathrm{g} / \mathrm{kg} / \mathrm{min}$ ), disengaging the guiding catheter from the coronary ostium, a set-up that allows us to make a pull-back recording that will prevent most of the technical problems and enables us to notice important step-ups in the pressure recording.

One last consideration relates to the applicability of FFR in heart failure. When using the equation $\mathrm{FFR}=\mathrm{Pd} / \mathrm{Pa}$, the assumption is that the venous pressure $(\mathrm{Pv})$ equals 0 , or, at least it is negligible compared to the arterial pressure. This may not be the case in severe heart failure with extremely elevated venous pressures. However, it will only affect the negative predictive value of FFR, i. e. a positive FFR $(\leq 0,80)$ will mean a significant stenosis all the same, and for scientific purposes, FFR can be calculated as follows: $\mathrm{FFR}=(\mathrm{Pd}-\mathrm{Pv}) /(\mathrm{Pa}-\mathrm{Pv})$. However, in the vast majority of cases, FFR can be reliably measured without determining the central venous pressure [17].

\section{References}

1. Lin GA, Dudley RA, Lucas FL, Malenka DJ, Vittinghoff E, et al. (2008) Frequency of stress testing to document ischemia prior to elective percutaneous coronary intervention. JAMA 300: 1765-73.

2. Topol EJ, Nissen SE (1995) Our preoccupation with coronary luminology. The dissociation between clinical and angiographic findings in ischemic heart disease. Circulation 92: 2333-42.

3. Toth G, Hamilos M, Pyxaras S, Mangiacapra F, Nelis O, et al. (2014) Evolving concepts of angiogram: fractional flow reserve discordances in 4000 coronary stenoses. Eur Heart J 35: 2831-8.

4. Windecker S, Kolh P, Alfonso F, Collet JP, Cremer J, et al. (2014) 2014 ESC/EACTS Guidelines on myocardial revascularization. The Task Force on Myocardial Revascularization of the European Society of Cardiology (ESC) and the European Association for Cardio-Thoracic Surgery (EACTS). Developed with the special contribution of the European Association of Percutaneous Cardiovascular Interventions (EAPCI). Eur Heart J 35: 2541 -619. 
5. Tonino PA, De Bruyne B, Pijls NH, Siebert U, Ikeno F, et al. (2009) Fractional flow reserve versus angiography for guiding percutaneous coronary intervention. N Engl J Med 360: 213-24.

6. Pijls NH, Fearon WF, Tonino PA, Siebert U, Ikeno F, et al. (2010) Fractional Flow Reserve Versus Angiography for Guiding Percutaneous Coronary Intervention in Patients With Multivessel Coronary Artery Disease. 2-Year Follow-Up of the FAME Study. J Am Coll Cardiol 56: 177-84.

7. van Nunen LX, Zimmermann FM, Tonino PAL, Barbato E, Baumbach A, et al. (2015) Fractional flow reserve versus angiography for guidance of PCI in patients with multivessel coronary artery disease (FAME): 5-year follow-up of a randomised controlled trial. Lancet 386: 1853-60.

8. De Bruyne B, Sarma J (2008) Fractional flow reserve: a review. Heart 94: 949-59.

9. Pijls NH, Klauss V, Siebert U, Powers E, Takazawa K, et al. (2002) Coronary pressure measurement after stenting predicts adverse events at follow-up: a multi-center registry. Circulation 105: 2950-4.

10. Rimac G, Fearon WF, De Bruyne B, Ikeno F, Matsuo H, et al. (2017) Clinical value of post-percutaneous coronary intervention fractional flow reserve value: A systematic review and meta-analysis. Am Heart J 183: 1-9.

11. Piroth Z, Toth GG, Tonino PAL, Barbato E, Aghlmandi S, et al. (2017) Prognostic Value of Fractional Flow Reserve Measured Immediately After Drug-Eluting Stent Implantation. Circ Cardiovasc Interv 2017; 10: e005233. DOI: 10.1161/CIRCINTERVENTIONS.116.005233.

12. Doh JH, Nam CW, Koo BK, Lee SY, Choi H, et al. (2015) Clinical relevance of poststent fractional flow reserve after drug-eluting stent implantation. J Invasive Cardiol 27: 346-51.

13. Nam CW, Hur SH, Cho YK, Park HS, Yoon HJ, et al. (2011) Relation of fractional flow reserve after drug-eluting stent implantation to one-year outcomes. Am J Cardiol 107: 1763-7.

14. Leesar MA, Satran A, Yalamanchili V, Helmy T, Abdul-Waheed M, et al. (2011) The impact of fractional flow reserve measurement on clinical outcomes after transradial coronary stenting. EuroIntervention 7: 917-23.

15. Matsuo A, Fujita H, Tanigaki T, Shimonaga T, Ueoka A, et al. (2013) Clinical implications of coronary pressure measurement after stent implantation. Cardiovasc Interv Ther 28: 170-7.

16. Tonino PA, Johnson NP (2016) Why is fractional flow reserve after percutaneous coronary intervention not always 1.0?. JACC Cardiovasc Interv 9: 1032-5.

17. Toth GG, De Bruyne B, Rusinaru D, Di Gioia G, Bartunek J, et al. (2016) Impact of right atrial pressure on fractional flow reserve measurements: Comparison of fractional flow reserve and myocardial fractional flow reserve in 1,600 coronary stenoses. JACC Cardiovasc Interv 9: 453-9. 